\title{
La cultura organizacional como base para la permanencia en las organizaciones.
}

\section{Organizational culture as a basis for the permanence of organizations.}

\author{
Autores \\ María Olivia Palafox Soto. Instituto Tecnológico de Sonora. México. \\ E-mail: marioly95@,hotmail.com https://orcid.org/0000-0002-8245-3032 \\ Sergio Ochoa Jiménez. Instituto Tecnológico de Sonora. México. \\ E-mail:sochoa@itson.edu.mxhttps://orcid.org/0000-0003-1848-3760 \\ Carlos Armando Jacobo Hernández. Instituto Tecnológico de Sonora. México. \\ E-mail: cjacobo@itson.edu.mx http://orcid.org/0000-0002-8524-6258
}

Fecha de recibido: 2019-09-06

Fecha de aceptado para publicación: 019-12-17

Fecha de publicación: 2019-12-30

\section{Resumen.}

Los estudios de cultura organizacional son cada vez más relevantes en el panorama actual, debido a su importancia como activo intangible de la organización, es por ello que el presente trabajo tiene como finalidad identificar los elementos que conforman la cultura organizacional por medio de una revisión sistemática, que contribuya al buen funcionamiento y permanencia de las organizaciones a través del tiempo. Los principales hallazgos afirman que el bienestar laboral, misión, visión, valores, objetivos, liderazgo, participación, entre otros elementos influyen en la permanencia de las empresas. Por ello, se recomienda que las organizaciones den primordial importancia a los aspectos que configuran la cultura, contribuyendo a que las empresas subsistan a través del tiempo, además de seguir realizando revisiones de literatura de este tipo como base importante para futuras investigaciones.

Palabras clave: Cultura organizacional; elementos; organizaciones; permanencia; investigaciones

\begin{abstract}
.
The studies of organizational culture are increasingly relevant in the current panorama, due to its importance as an intangible asset of the organization, therefore this work aims to identify the elements that make up the organizational culture through a literature review that contributes to the good performance and permanence of organizations over the time. The main findings affirm that labor wellbeing, mission, vision, values, objectives, leadership, participation, among others elements influence the permanence of companies. Therefore, it is recommended that organizations give paramount importance to the aspects that make up the culture, contributing to companies subsisting over time, in addition to continuing to review literature of this type as an important basis for future research.
\end{abstract}

Keywords: Organizational culture; elements; organizations; permanence; researches. 


\section{Introducción}

El término de cultura hace referencia a un conjunto de creencias y significados compartidos que determinan la forma de trabajar de las organizaciones (Cújar, Ramos, Hernández \& López, 2013) también es conocida como un patrón de supuestos creados por un grupo de personas que permiten solucionar diversas problemáticas de tal forma que puedan percibirlas, razonarlas y darles solución alguna (Schein, 1983). Además de permitir la interacción y relación de creencias, tradiciones, valores, costumbres, entre otros aspectos (Rodríguez, 2009). De la misma forma, de acuerdo con Arboleda y López (2017) este aspecto también es conocido como un conjunto de creencias dentro de las organizaciones; o bien también es caracterizado como aquello que las organizaciones posee (Montaña \& Torres, 2015).

Con el paso del tiempo el término de cultura, su importancia y relevancia fueron en crecimiento desde los años 70s (Pedraza-Álvarez, Obispo-Salazar, Vásquez-González \& Gómez-Gómez, 2015) hasta el punto de existir infinidad de formas en las que fue usado para los análisis y estudios organizacionales, además es innegable decir que dicho concepto se define dependiendo de la manera en que las personas perciban tanto a la organización como a la cultura (García, 2006).

La cultura organizacional se caracteriza por la manera en que las personas conviven e interactúan con sus compañeros o la sociedad en general, además de las distintas formas de trabajar dentro de la organización (Cantú, 2001) sobre todo porque permite moldear el comportamiento de los integrantes de la misma (Carrillo, 2016). Este aspecto consiste en que los trabajadores operen su trabajo con gusto y sobre todo tratar de hacerlos sentir que son parte de la misma (Chabaud, 2007). Es importante tener en cuenta que también se busca lograr un compromiso con la empresa y que los trabajadores sean felices de trabajar en ella.

Además, el tema de cultura organizacional ha sido abordado por diversos autores de en diversas investigaciones, que favorece el enriquecimiento de dicha variable y muestra lo importante que ha sido y seguirá siendo para las organizaciones, además de dejar en claro como las empresas pueden lograr mejores resultados gracias a la cultura organizacional que poseen, de acuerdo con Berson, Oreg y Dvir (2008) mencionan que también permite obtener resultados firmes.

Hoy en día, el mundo está más globalizado, la competencia va en aumento, por lo que entrar y permanecer a los mercados se vuelve cada vez más complejo, pues el impacto de la globalización cultural está logrando que la competencia sea más acelerada de tal forma que logren el éxito y la 
permanencia de las mismas (Gómez, 2008). Por lo cual adentrarse en aspectos blandos de la organización ofrece grandes beneficios para la misma, que logra crecimiento, eficacia, y éxito (Alvesson, 2013).

Es por ello que las empresas buscan que sus trabajadores desarrollen un sentido de lealtad y pertenencia hacia la propia organización volviéndose más productivos y, favoreciendo así al desarrollo de diversos elementos que conforman una cultura organizacional tales como su misión, visión, valores, etc. siendo también un marco de referencia y distinción ante la competencia (Pous, 2007).

Aunado a lo anterior, este aspecto es de gran relevancia en el análisis de las organizaciones debido a que todas las estrategias, actividades, funciones y procesos que se realicen en las empresas son gestionados por personas y éstos llevan a cabo sus funciones de acuerdo a la cultura organizacional en la que se encuentren, siendo además un factor determinante en el subsistir de las mismas.

Así pues, la presente investigación tiene por objetivo identificar los elementos que conforman la cultura organizacional por medio de una revisión de literatura que contribuya al buen funcionamiento y permanencia de las organizaciones a través del tiempo.

\section{Metodología}

Para realizar la presente investigación se tomó en consideración la metodología de una revisión sistemática, ya que dicho método permite una búsqueda más acorde al tema de investigación (Manchado, Tamames, López, Mohedano y Veiga de Cabo, 2009) para describir el conocimiento ya existente y poder generar nuevas propuestas de investigación.

Primero, se realizó una búsqueda de información en diversas bases de datos: Redalyc, Ebsco, Scielo, Elsevier, Wiley, con la ayuda de palabras clave. Después fueron tomados en cuenta parámetros de inclusión, tales como: el idioma inglés y español, con interés en artículos relacionados al tema, fueron aceptadas todos los tipos investigaciones, en lo que respecta a los años de actualidad, se trabajó con artículos de actualidad y con otros de mayor antigüedad por la importancia de las investigaciones realizadas como base para la presente investigación. En cuanto a los paramentos de exclusión: no se admitieron las tesis de pregrado.

En un tercer momento, se procuró que las investigaciones encontradas tomaran en cuenta a la variable de cultura en general para conocer si dentro de la misma examinaban lo que se pretende 
en el objetivo de dicha investigación, sin embargo, solo se tomaron en cuenta aquellas que mencionaban elementos de la cultura organizacional para el procesamiento de información con la finalidad de ayudar a la permanencia de las empresas y al buen funcionamiento de las mismas.

\section{Resultados y Discusión}

El estudio de la cultura antecede a principios de los años ochenta y ha estado tomando fuerza en los últimos años, gracias a ser considerado un elemento fundamental en las organizaciones (García, 2007). Por lo que, el análisis de los elementos que la componen se muestra a partir de las investigaciones realizadas por diversos autores, contrastado con lo que establecen otros en sus estudios.

De acuerdo con Huang (2005), afirma que la cultura organizacional permite que las empresas puedan conocer sus aspectos, tanto positivos como negativos y logra desarrollar estrategias que les ayudan a identificar fortalezas y debilidades, que tengan un impacto en el rendimiento, consiguiendo así la permanencia dentro del mercado; lo que permite que dichos elementos ayuden a elevar la productividad (Salazar, Guerrero, Machado \& Cañedo, 2009).

La cultura organizacional permite reflejar el comportamiento de las organizaciones; es decir como los empleados hacen su trabajo, así como el trato hacia los demás dentro y fuera de la misma, por lo que es importante que el marketing se haga presente en la organización (Wilson, 2001) con la finalidad de que conozca mejor su mercado y se adapte rápidamente para cumplir con las necesidades de los mismos (Giraldo \& Esparragoza, 2016). Sin embargo, Páramo (2001) menciona que una empresa con una cultura enfocada al mercado es una labor demasiado complicada y difícil por todo lo que el marketing requiere.

Otros elementos que se encuentran estrechamente relacionados con la cultura organizacional son el ambiente laboral y el trabajo en equipo, con la finalidad de tener buena comunicación dentro de la empresa (Borda, Rodríguez, \& Guarín 2011), así como la misión, visión y valores planteado por (Pous, 2007), considerados también como características primordiales sobre dicho aspecto.

Es importante también evidenciar las ventajas que trae consigo la cultura organizacional ya que la competitividad y el logro de objetivos se convierten en dos elementos más que brindan una óptima cultura dentro de las organizaciones (Restrepo, Fajardo \& Ladino, 2007); además, de acuerdo con Mahler (1997) menciona que el logro de objetivos se obtiene porque la cultura va 
encaminada a obtener un mejor aprendizaje permitiendo resolver situaciones que se vuelven problemáticas dentro de la organización.

Según Contreras y Hernández (2011) afirman que en el análisis de los elementos que conforman a la cultura organizacional se encuentran: la identidad, imagen, visión, misión, lógica etc. y que son reconocidos por diversos investigadores; así como el liderazgo ejercido dentro de las organizaciones, encontrando diversos estudios que analizan su relación (León, 2001), que hace posible que el ambiente de trabajo sea armónico y saludable (Shirey, 2009).

Cabe mencionar, que es relevante conocer la cantidad de investigaciones realizadas sobre cultura organizacional que permiten encontrar la relación que guarda con elementos que son relevantes para la gestión y permanencia de las organizaciones, tal como Calderón, Murillo y Torres (2003) quienes analizan la cultura con el bienestar social mostrando evidencia del alto nivel que tiene la relación entre ambos aspectos. Aunado a lo anterior Finder, Wind y Mor (2008) también opinan que el bienestar, compromiso, equidad, apoyo y satisfacción son elementos que permiten cambios significativos en la cultura de la empresa.

De acuerdo con Segrera, Corredor y Labarcés (2014) mencionan que el abordaje de los elementos que intervienen en la cultura organizacional establece una relación existente con el rendimiento laboral, la productividad y el logro de objetivos, además de la buena comunicación, logrando conseguir la solución a distintos problemas, el apoyo mutuo entre compañeros y un buen clima laboral.

Por lo que Wallingre (2005) asegura que la cultura permite tener buenas conductas que mejoran tanto la calidad como el servicio en las organizaciones con el fin de fomentar el desarrollo económico y social de los países, estableciendo que la cultura organizacional debe estar estructurada en tres elementos básicos que deben considerarse como sus principios, los cuales son la participación de toda la organización, la creatividad que permita lograr la innovación y la aceptación de riesgos; además se ha demostrado que la innovación tiene un impacto de mejora tanto en la cultura como el aprendizaje organizacional (Skerlavaj, Song \& Lee, 2010).

A continuación, se muestra de manera gráfica en la Tabla 1, los elementos que cada uno de los autores exponen sobre dicho aspecto y cómo a través del tiempo se siguen retomando y agregando otros más que son considerados de importancia dentro de las mismas.

Tabla 1.- Elementos de cultura organizacional tratados por los autores estudiados 


\begin{tabular}{|c|c|}
\hline Autores & Elementos \\
\hline Mahler (1997) & $\begin{array}{l}\text { Aprendizaje } \\
\text { Logro de objetivos }\end{array}$ \\
\hline León (2001) & Liderazgo \\
\hline $\begin{array}{l}\text { Giraldo y Esparragoza (2016); } \\
\text { Páramo (2001) }\end{array}$ & Enfoque hacia el mercado \\
\hline Wilson, 2001) & Marketing \\
\hline Calderón, Murillo y Torres (2003) & Bienestar social \\
\hline Wallingre (2005) & $\begin{array}{l}\text { Participación } \\
\text { Creatividad } \\
\text { Innovación }\end{array}$ \\
\hline (Pous, 2007) & $\begin{array}{l}\text { Misión } \\
\text { Visión } \\
\text { Valores } \\
\end{array}$ \\
\hline Restrepo, Fajardo y Ladino (2007) & $\begin{array}{l}\text { Competitividad } \\
\text { Logro de objetivos }\end{array}$ \\
\hline Finder, Wind y Mor (2008) & $\begin{array}{l}\text { Bienestar } \\
\text { Compromiso } \\
\text { Equidad } \\
\text { Apoyo } \\
\text { Satisfacción }\end{array}$ \\
\hline Shirey (2009) & Ambiente de trabajo \\
\hline $\begin{array}{l}\text { Salazar, Guerrero, Machado y } \\
\text { Cañedo (2009) }\end{array}$ & $\begin{array}{l}\text { Productividad } \\
\text { Rendimiento }\end{array}$ \\
\hline Borda, Rodríguez y Guarín (2011) & $\begin{array}{l}\text { Ambiente laboral } \\
\text { Trabajo en equipo } \\
\text { Comunicación }\end{array}$ \\
\hline Contreras y Hernández (2011) & $\begin{array}{l}\text { Identidad } \\
\text { Imagen } \\
\text { Misión y visión } \\
\text { Lógica }\end{array}$ \\
\hline $\begin{array}{l}\text { Segrera, Corredor y Labarcés } \\
\text { (2014) }\end{array}$ & $\begin{array}{l}\text { Rendimiento laboral } \\
\text { Productividad } \\
\text { Logro de objetivos } \\
\text { Apoyo mutuo } \\
\text { Comunicación y } \\
\text { Clima laboral }\end{array}$ \\
\hline
\end{tabular}

Dada la importancia que mantiene la cultura organizacional es indispensable conocer los elementos que la conforman y lo fundamental que resultan para lograr los objetivos propuestos permitiendo que las organizaciones trabajen de manera óptima para que subsistan a través del tiempo. 
Todos y cada uno de los autores exponen distintos elementos y algunos similares, demostrando también que todos ayudan a que la organización sea un lugar mejor para trabajar, entendiendo que la cultura organizacional puede presentarse de diferentes formas, en diferentes lugares y con distintas posturas, dependiendo de cada organización y del ambiente que exista dentro de la misma.

Por todo lo analizado anteriormente en la literatura es importante resaltar que la cultura es un aspecto imperativo que las organizaciones deben mantener siempre firmes, ya que los elementos que la conforman inciden en gran medida en el buen funcionamiento y en la permanencia de las mismas

\section{Conclusiones}

Finalmente, la cultura es un aspecto fundamental de las organizaciones, pues gestionándola correctamente y de la mejor manera posible, permite conseguir un buen ambiente y clima laboral, además de que los trabajadores se sientan orgullosos de laborar en las organizaciones, sobre todo porque puede influir de manera positiva dependiendo de la actitud y conducta presente en cada una de ellas, al mismo tiempo busca que los trabajadores se sientan más satisfechos y de esta manera logren conseguir el éxito y una ventaja competitiva al tener al personal adecuado y satisfecho trabajando con la empresa.

La cultura organizacional trae consigo aspectos positivos, como el cumplir con las estrategias para laborar de forma óptima y que los empleados puedan adoptar una cultura fuerte y saludable, no solo para trabajar, sino para hacerla parte de sus valores y también de su cultura personal, no obstante, pueden ocurrir aspectos negativos para la empresa, si no se le otorga la atención debida, pues podría perjudicar a los empleados y a sus actividades dentro de la organización.

Cabe señalar, que los elementos encontrados en la literatura se relacionan de forma directa e indirectamente con la cultura organizacional, encontrando que todos están en torno a lo que sucede con los individuos, ya que es el activo más importante y complejo dentro de una empresa y por el cual las organizaciones tienden a ir al éxito o al fracaso.

Además, si en las empresas existen problemas entre los individuos, es importante dar a conocer y exaltar la relevancia de la cultura organizacional, buscando generar un ambiente laboral agradable y permitiendo que todos puedan comprender las actividades que deben hacer y cómo 
se deben realizar para alcanzar una mayor eficiencia y poder generar un valor hacia los clientes, logrando la competitividad y permanencia.

Con base en lo anteriormente expuesto, son diversas las ventajas que tiene este aspecto y centrarse en los elementos que la configuran trae consigo grandes beneficios para las organizaciones, por lo que se recomienda seguir realizando revisiones de literatura de este tipo, que ayuden a futuras investigaciones, ya sea empíricas o teóricas contribuyendo a la importancia de contar con una óptima cultura organizacional.

\section{Aspectos a destacar}

Publicación financiada con recursos del Programa Fortalecimiento de la Calidad Educativa (PFCE) de la Secretaría de Educación Pública (SEP) de México y del Programa de Fomento y Apoyo a Para la Investigación (PROFAPI-ITSON).

\section{Referencias bibliográficas}

Alvesson, M. (2012). Understanding organizational culture. SAGE: England.

Arboleda, G., \& López, J. (2017). Cultura organizacional en las instituciones prestadoras de servicios de salud del Valle de Aburrá. Revista ciencias de salud, 15(2), 247-258.

Berson, Y., Oreg, S., \& Dvir, T. (2008). CEO Values, Organizational Culture and Firm Outcomes. Journal of Organizational Behavior, 29(5), 615-633.

Borda, A., Rodríguez, C., \& Guarín, H. (2011). Diagnóstico de cultura organizacional en el hotel grand house. (Tesis de maestría inédita). Universidad de la Sabana, Bogotá. Recuperado de

http://intellectum.unisabana.edu.co/bitstream/handle/10818/211/Ana\%20Mar\%C3\%ADa $\%$ 20Borda\%20Clopatofsky.pdf?sequence $=1$

Calderón, G., Murillo, S., \& Torres, K. (2003). Cultura organizacional y bienestar laboral. Cuadernos de Administración, 16(25), 109-137.

Cantú D., H. (2001). Desarrollo de una cultura de calidad. México. McGraw-Hill. Interamericana Editores, SA de CV.

Carrillo, A. (2016). Medición de la cultura organizacional. Ciencias Administrativas, 8, 1-23. Recuperado de https://www.redalyc.org/jatsRepo/5116/511653788007/html/index.html 
Chabaud, P. (2007). Cultura organizacional e identidad. Hospitalidad-Esdai, México,25-45.

Contreras, A., \& Hernández, E. (2011). Antecedentes teóricos y niveles de análisis de la identidad organizacional. Nova Scientia, 3(6), 158-179.

Cújar, A., Ramos, C., Hernández, H., \& López, J. (2013). Cultura organizacional: evolución en la medición. Estudios Gerenciales, 29, 350-355.

Finder, L., Wind, L., \& Mor, M. (2008). Modeling the Relationship between Diversity, Inclusion, Organizational Culture, and Employee Well-Being, Job Satisfaction and Organizational. Commitment. Administraion in social work, 31(3), 63-94. DOI: $10.1300 / \mathrm{J} 147 \mathrm{v} 31 \mathrm{n} 03 \_05$.

García, C. (2006). Una aproximación al concepto de cultura organizacional. Universitas Psychologica, 5(1), 163-174.

García, O. (2007). La cultura humana y su interpretación desde la perspectiva de la cultura organizacional. Pensamiento y gestión, 22, 143-154.

Giraldo, M., \& Esparragoza, D. (2016). Gerencia de marketing. ECOE Ediciones: Colombia.

Gómez, M. (2008). Cultura organizacional e identidad productiva propuesta para el análisis de las organizaciones colombianas. Umbral cientifico, 1(13), 56-64.

Huang, H. (2005). Investigation of the fit among current and preferred organizational cultures, personality styles, and job attitudes in employees of international tourist hotels in Taiwan. ProQuest: Idaho State University

León, R. (2001). Cultura organizacional y liderazgo: Reflexiones sobre algunos resultados de entidades bancarias. Revista de Psicología del Trabajo y de las Organizaciones, 17(2), $155-172$.

Mahler, J. (1997). Influences of Organizational Culture on Learning in Public Agencies. Journal of Public Administration Research and Theory, 7(4), 519-540. doi: 10.1093/oxfordjournals.jpart.a024364.

Manchado, R., Tamames, S., López, M., Mohedano, L., \& Veiga de Cabo, J. (2009). Revisiones sistemáticas exploratorias. Medicina y seguridad del trabajo, 55(216), 12-19. Recuperado de http://scielo.isciii.es/pdf/mesetra/v55n216/especial.pdf

Montaña, A., \& Torres, G. (2015). Caracterización de la cultura organizacional y lineamientos de intervención para la implementación de proceso de cambio en las organizaciones caso empresa sector financiero. (Tesis inédita de maestría). Universidad del Rosario, Bogotá. 
https://repository.urosario.edu.co/flexpaper/handle/10336/10104/TorresReyes-

GermanAlonso-2014.pdf?sequence $=5$ \&isAllowed $=\mathrm{y}$

Páramo, D. (2001). Hacia la construcción de un modelo de cultura organizacional orientada al mercado. Revista Colombiana de Marketing, 2(2), 1-27.

Pedraza-Álvarez, L., Obispo-Salazar, K., Vásquez-González, L., \& Gómez-Gómez, L. (2015). Cultura organizacional desde la teoría de Edgar Schein. Estudio fenomenológico. Revista Clío América, 9(17), 17-25. Recuperado de file://C:/Users/hp/Downloads/DialnetCulturaOrganizacionalDesdeLaTeoriaDeEdgarSchein-5139907.pdf

Pous, G. C. (2007). Cultura organizacional e identidad. Hospitalidad ESDAI, 1(11), 25-45.

Restrepo, L., Fajardo, F., \& Ladino, A. (2007). Cambio de cultura organizacional para empresas que requieren evolucionar hacia la competitividad. Scientia et Technica, 1(35), 327-332.

Rodríguez, R. (2009). La cultura organizacional. Un potencial activo estratégico desde la perspectiva de la administración. Invenio, 12(22), 67-92.

Salazar J., Guerrero, J., Machado, Y., \& Cañedo, R. (2009). Clima y cultura organizacional: dos componentes esenciales en la productividad laboral. ACIMED, 20(4), 67-75.

Schein, E. (1983). The Role of the Founder in the Creation of Organizational Culture. Organizational dynamics, 12(1) 13-28.

Segrera, J., Corredor, A., \& Labarcés, C. (2014). La cultura organizacional de los operadores turísticos de Santa Marta 2012- 2013. Clio América, 8(15), 22-35.

Shirey, M. (2009). Authentic Leadership, Organizational Culture, and Healthy Work Environments. Critical Care Nursing Quarterly 32(3), 189,198. DOI: 10.1097/CNQ.0b013e3181ab91db.

Skerlavaj, M., Song, J., \& Lee, Y. (2010). Organizational learning culture, innovative culture and innovations in South Korean firms. Expert Systems with Applications, 37(9), 6390-6403, 6390-6403. https://doi.org/10.1016/j.eswa.2010.02.080.

Wallingre, N. (2005). La necesidad de implementar una cultura organizacional innovadora en las Pymes hoteleras de Argentina. Tiempo de Gestión, 1(1), 83-93.

Wilson, AM (2001). Understanding organizational culture and the implications for corporate marketing. European Journal of Marketing, 35(3/4), 353-367. DOI: 10.1108 / 03090560110382066. 
REVISTA SAN GREGORIO, 2019, No.35, OCTUBRE-DICIEMBRE (202-212), ISSN: 1390-7247; EISSN: 2528- 